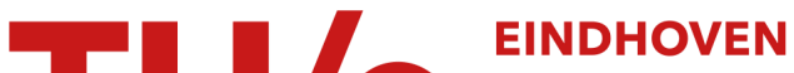 UNIVERSITY OF TECHNOLOGY
}

\section{Light-driven electrohydrodynamic instabilities in liquid crystals}

Citation for published version (APA):

Zhan, Y., Schenning, A. P. H. J., Broer, D. J., Zhou, G., \& Liu, D. (2018). Light-driven electrohydrodynamic instabilities in liquid crystals. Advanced Functional Materials, 28(21), [1707436].

https://doi.org/10.1002/adfm.201707436

\section{Document license:}

TAVERNE

DOI:

10.1002/adfm.201707436

Document status and date:

Published: 24/05/2018

\section{Document Version:}

Publisher's PDF, also known as Version of Record (includes final page, issue and volume numbers)

\section{Please check the document version of this publication:}

- A submitted manuscript is the version of the article upon submission and before peer-review. There can be important differences between the submitted version and the official published version of record. People interested in the research are advised to contact the author for the final version of the publication, or visit the $\mathrm{DOI}$ to the publisher's website.

- The final author version and the galley proof are versions of the publication after peer review.

- The final published version features the final layout of the paper including the volume, issue and page numbers.

Link to publication

\section{General rights}

Copyright and moral rights for the publications made accessible in the public portal are retained by the authors and/or other copyright owners and it is a condition of accessing publications that users recognise and abide by the legal requirements associated with these rights.

- Users may download and print one copy of any publication from the public portal for the purpose of private study or research.

- You may not further distribute the material or use it for any profit-making activity or commercial gain

- You may freely distribute the URL identifying the publication in the public portal.

If the publication is distributed under the terms of Article $25 f a$ of the Dutch Copyright Act, indicated by the "Taverne" license above, please follow below link for the End User Agreement:

www.tue.nl/taverne

Take down policy

If you believe that this document breaches copyright please contact us at:

openaccess@tue.nl

providing details and we will investigate your claim. 


\title{
Light-Driven Electrohydrodynamic Instabilities in Liquid Crystals
}

\author{
Yuanyuan Zhan, Albertus P. H. J. Schenning, Dirk J. Broer, Guofu Zhou,* and Danqing Liu*
}

The induction of electrohydrodynamic instabilities in nematic liquid crystals through light illumination are reported. For this purpose, a photochromic spiropyran is added to the liquid crystal mixture. When an electrical field is applied in the absence of UV light, the homeotropic liquid crystal reorients perpendicular to the electrical field driven by its negative dielectric anisotropy. Upon exposure to UV light, the nonionic spiropyran isomerizes to the zwitterionic merocyanine form inducing electrohydrodynamic instabilities which turns the cell from transparent into highly scattering. The reverse isomerization to closed-ring spiropyran form occurs thermally or under visible light, which stops the electrohydrodynamic instabilities and the cell becomes transparent again. It is demonstrated that the photoionic electrohydrodynamic instabilities can be used for light regulation. Local exposure, either to drive the electrohydrodynamics or to remove them enables the formation of colored images.

windows. ${ }^{[4]}$ Such devices are most often based on mixtures of polymer and liquid crystals. ${ }^{[5]}$ For example, polymer dispersed liquid crystals (PDLCs) in which the scattering is based on the refractive index mismatch between a phase separated LC constituent and a polymer binder in the field-off state, ${ }^{[6]}$ while in polymer stabilized liquid crystals (PSLCs), the scattering appears in the field-on state and originates from a combination of polydomain formation and a refractive index mismatch between the LC and a liquid crystal polymer additive..$^{[7]}$ The electro-optical performances in both PDLCs and PSLCs strongly rely on the delicate control over the polymerization process and the choice of polymer and liquid crystals is critical. ${ }^{[8,9]}$

\section{Introduction}

Liquid crystals (LCs) are an interesting class of materials, especially for the large optical and dielectric anisotropy which forms the basis for a number of electro-optical effects. ${ }^{[1]}$ Electrically tunable birefringence is used for most liquid crystal displays..$^{[2]}$ For example, patterned LC alignment results in switchable gratings and optical lenses..$^{[3]}$ Light scattering effects, in which transparent and scattering states are modulated through an electric field, are presently the basis for the development of a variety of applications ranging from reflective displays to smart

Y. Zhan, Prof. A. P. H. J. Schenning, Prof. D. J. Broer, Prof. G. Zhou, Dr. D. Liu SCNU-TUE Joint Lab of Device Integrated Responsive Materials (DIRM)

National Center for International Research on Green Optoelectronics

South China Normal University

Guangzhou 510006, P. R. China

E-mail: guofu.zhou@m.scnu.edu.cn; d.liu1@tue.nl

Y. Zhan, Prof. A. P. H. J. Schenning, Prof. D. J. Broer, Prof. G. Zhou, Dr. D. Liu Laboratory of Functional Organic Materials and Devices (SFD)

Department of Chemical Engineering and Chemistry

Eindhoven University of Technology

Groene Loper 5, 5612 AE Eindhoven, The Netherlands

Prof. A. P. H. J. Schenning, Prof. D. J. Broer, Dr. D. Liu

Institute for Complex Molecular Systems (ICMS)

Eindhoven University of Technology

Groene Loper 5, 5612 AE Eindhoven, The Netherlands

Prof. G. Zhou

Shenzhen Guohua Optoelectronics Tech. Co. Ltd.

Shenzhen 518110, China

The ORCID identification number(s) for the author(s) of this article can be found under https://doi.org/10.1002/adfm.201707436.

DOI: $10.1002 / \mathrm{adfm} .201707436$
Polymer-free scattering devices are therefore appealing because of their simplicity of fabrication. ${ }^{[10]}$

In this work, we reevaluate an old principle based on electrohydrodynamic instabilities (EHDI) when an LC is subjected to an electric field. EHDI in LCs was discovered and reported already in the 1960s and was initially used to make scattering-based displays. ${ }^{[11,12]}$ EHDI requires the coexistence of two events, the reorientation of aligned LC and the motion of charge carriers under an electric field. Generally, homeotropically aligned LCs with a negative dielectric anisotropy are used that realign to a planar orientation. ${ }^{[13]}$ Charge carriers are often added to increase the conductivity and thereby reduce the switching voltage of the EHDI effect. ${ }^{[14]}$ In the current work, we propose to generate the ionic species by light. Thereto, we use a photochromic dye to create charge carriers by light. Using light as a contactless and remote stimulus would enable us to fabricate dual responsive and patterned addressable colored scattering devices by local exposure. ${ }^{[15,16]}$

For our experiments, an LC mixture with a negative dielectric anisotropy $(\Delta \varepsilon=-8.3)$ was selected. In a first reference experiment, hexadecyltrimethylammonium bromide (CTAB) was added as electrolyte to study EHDI of the LC mixture. The CTAB-doped LC mixture is placed in a cell constructed with two glass plates provided with transparent electrodes and homeotropic alignment layers. The LC is initially homeotropically aligned (Figure 1a,c) and shows a high light transmittance (Figure 1e). When applying an external alternating electric (AC) field of $20 \mathrm{~V}_{\mathrm{rms}}$ across the cell, the initially homeotropically oriented liquid crystals tilt $90^{\circ}$ toward a polydomain planar orientation. Meanwhile, the mobile charge carriers start oscillating under the influence of the AC field generating chaotic turbulence (Figure 1b,d,). Consequently, the LC strongly scatters light and completely shields the 
a
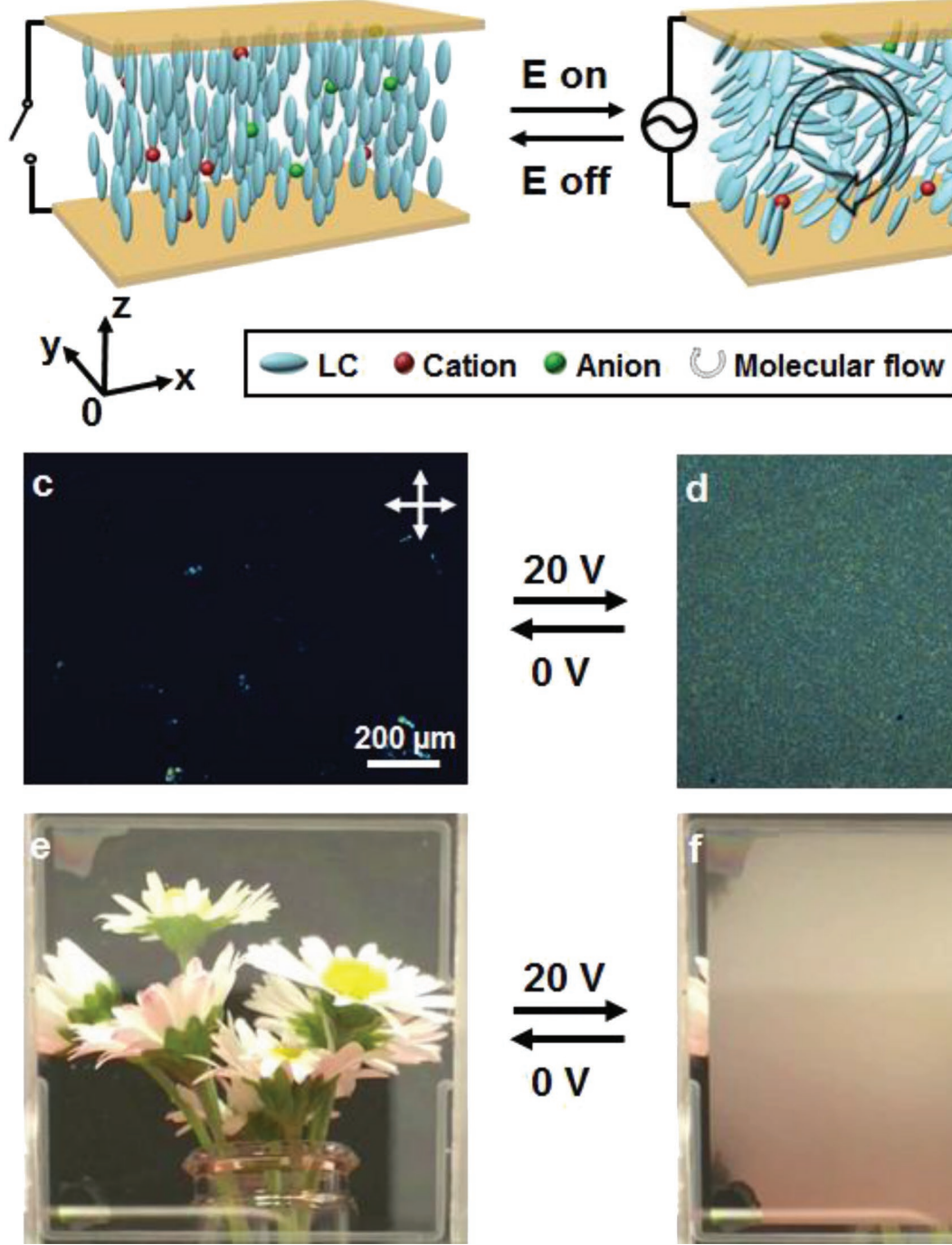
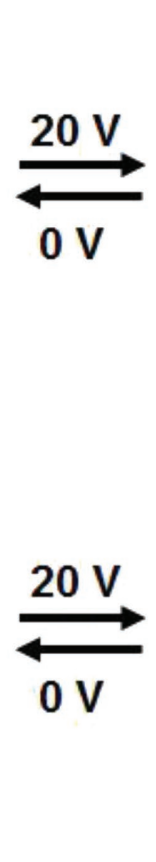

b

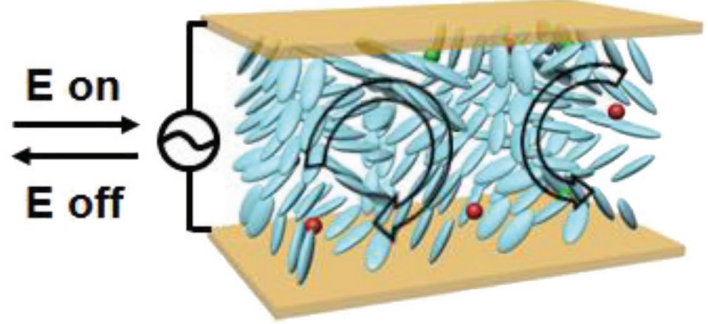

Molecular flow
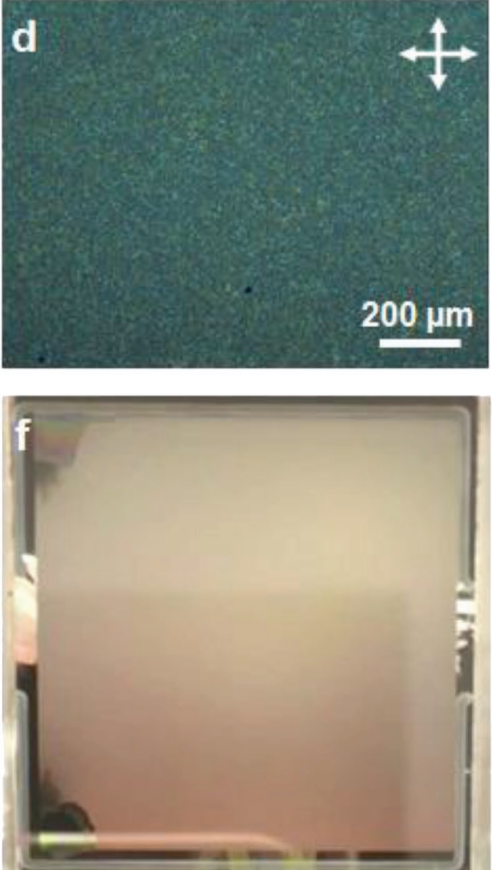

Figure 1. Electrohydrodynamic instability in a CTAB-doped LC mixture. Schematic representation of a) homeotropically aligned LC mixture in a cell at $0 \mathrm{~V}_{\mathrm{rms}}$ and $\mathrm{b}$ ) under an alternating electric field of $20 \mathrm{~V}_{\mathrm{rms}}$ at $50 \mathrm{~Hz}$ showing EHDI. Cross-polarized optical microscopy image showing c) initial homeotropic orientated LC at $0 \mathrm{~V}_{\mathrm{rms}}$ and d) turbulence patterns formed in the $\mathrm{LC}$ at $20 \mathrm{~V}_{\mathrm{rms}}$ and $50 \mathrm{~Hz}$. e) The transparent state at $0 \mathrm{~V}_{\mathrm{rms}}$ showing the flowers placed behind the cell, and f) the light scattering state under $20 \mathrm{~V}_{\mathrm{rms}}$ at $50 \mathrm{~Hz}$ which hides the flowers. The voltage described in the pictures is the root-mean-square voltage. The cell gap is $10 \mu \mathrm{m}$.

background (Figure 1f). The EHDI effect stops when the electric field is switched off and the initial homeotropic LC orientation and highly transparent state reverts immediately within $10 \mathrm{~s}$.

In order to fabricate dual responsive colored scattering devices, we added the photochromic $1^{\prime}, 3^{\prime}$-dihydro- $1^{\prime}, 3^{\prime}, 3^{\prime}$ trimethyl-6-nitrospiro[2H-1-benzopyran-2,2'-(2H)-indole], further denoted as the spiropyran, instead of CTAB to the LC mixture. The spiropyran aligns with the LC host (Figure 2a,d; Table S1 and Figure S2, Supporting Information). ${ }^{[17]}$ Moreover, it can be switched reversibly by UV light from the nonionogenic ringclosed spiropyran form (SP) to the blue zwitterionic merocyanine open form (MC) (Figure S1, Supporting Information). Based on this, we can reversibly modulate the scattering and color of the LC device by light and electricity. As with the SP-doped sample, when applying an external AC field, SP-doped LC is reoriented perpendicularly to the electric field line resulting in a planar alignment (Figure 2b). Since the alignment layer does not give a preferred reorientation direction, a random polydomain texture is formed which is characterized by point disclinations connected by line disclinations. The director describes a complex rotation on its transition from one domain into the other which becomes visible when observed between cross polarizers in optical microscopy. Since the LC is not homogenously aligned in the mono-domain fashion, minor light scattering appears yet the sample still exhibits highly optical transparence (Figure $2 \mathrm{~h}$ ). When addressed with UV light $(\lambda=365 \mathrm{~nm})$ at low intensity $\left(18 \mathrm{~mW} \mathrm{~cm}{ }^{-2}\right)$ for $5 \mathrm{~s}$ the nonionogenic closed-ring SP form converts to the ionic open-ring $\mathrm{MC}$ form (the MC conversion is 


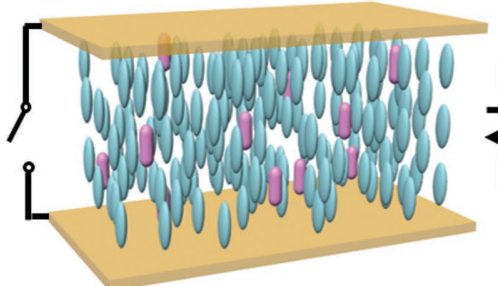

b

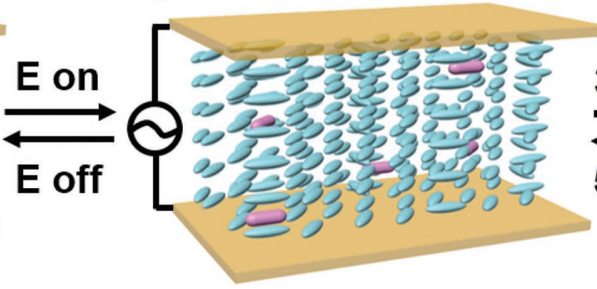

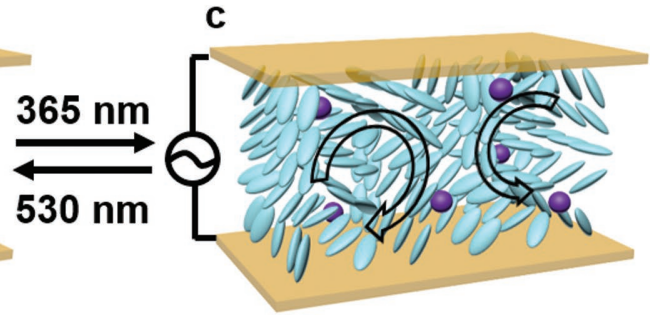
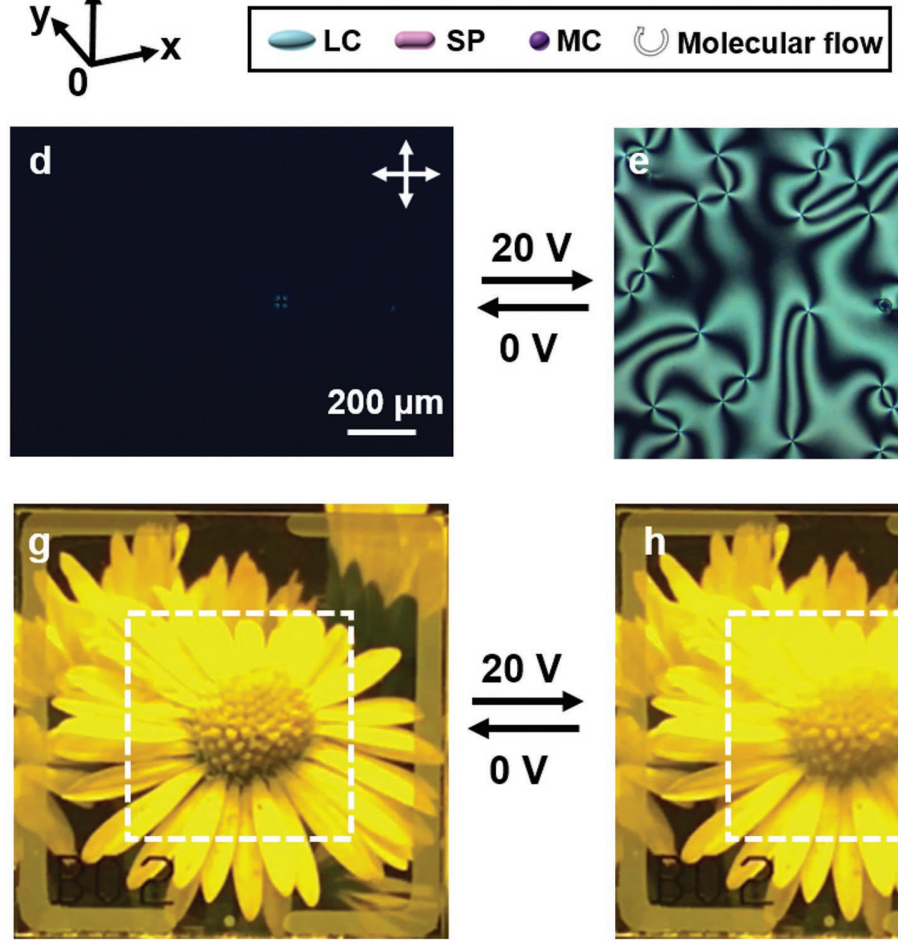
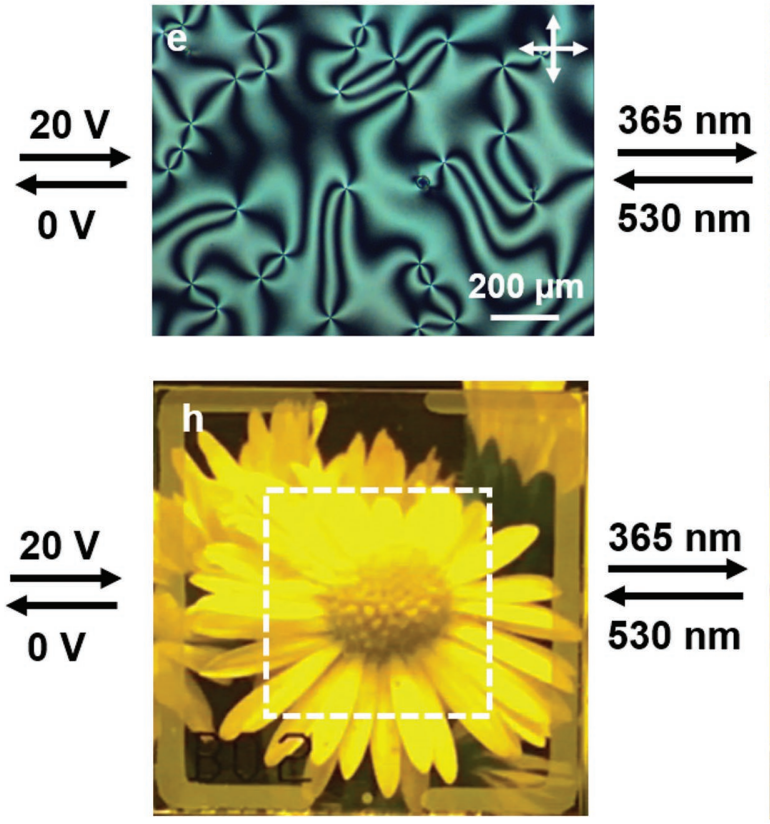

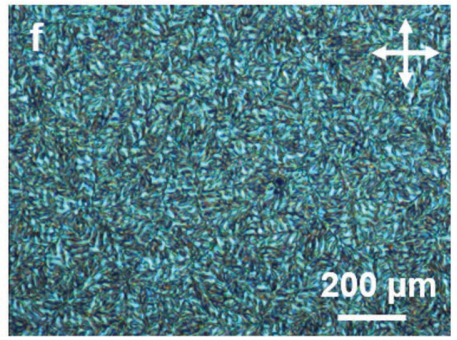

Figure 2. Light-induced EHDI. Schematic illustration of a) initial homeotropically aligned SP-doped LC at 0 V rms. b) LC realigns to random planar polydomain under the AC field of $20 \mathrm{~V}_{\text {rms }}$ at $50 \mathrm{~Hz}$. c) UV exposure converts SP to MC and initiates EHDI. d-f) The corresponding cross-polarized optical microscopic images of $(\mathrm{a})-(\mathrm{c})$, respectively. Photos show that the sample is g) transparent without electric field, h) slightly scattering under the electric field, and i) highly opaque when illuminated with UV light. The samples are kept in the laboratory with yellow light to avoid MC to SP back reaction. The dotted square highlights the active area of the sample with the dimension of $1 \mathrm{~cm} \times 1 \mathrm{~cm}$. The voltage described in the pictures is rootmean-square voltage. The cell gap is $9 \mu \mathrm{m}$.

given in Figure S3, Supporting Information). Consequently, the formed MC oscillates with the electric field which in combination with the realigned LCs triggers the EHDI (Figure 2c,f). Hence, strong light scattering is observed and the scattering cell shields the background (Figure 2i). The light scattered state is also colored correlating to the absorption spectrum of the $\mathrm{MC}$ isomer (Figure S1, Supporting Information). The EHDI and the corresponding light scattering stay for $10 \mathrm{~min}$ after switching off the UV irradiation (Figure S4, Supporting Information). The transparent state can be formed again by exposing the sample to green light at $\lambda=530 \mathrm{~nm}$ which stimulates the back isomerization to the SP form. Further switching off the external electric field, the LCs matrix recovers to the original homeotropic alignment.

To analyze the light-induced EHDI principle in more detail, we investigate first the input voltage and the corresponding output current (Figure 3a, Figure S5, Supporting Information). Before switching on the EHDI by UV light, a low current of $2 \mu \mathrm{A}$ is measured at $5 \mathrm{~V}_{\mathrm{rms}}$ which is comparable with LC mixture without SP. ${ }^{[18]}$ Upon UV exposure, the current increases significantly by a factor of 4 as the evidence of the formation of charge carriers upon the conversion of SP to the MC isomer. Next, we estimate the influence of electric field frequency and strength during UV light exposure. ${ }^{[19]}$ Figure $3 \mathrm{~b}$ shows the optimal frequency to trigger the EHDI is $50 \mathrm{~Hz}$. Below this value, the MC oscillation increases with frequency and a larger turbulence is generated and retained. Above the optimal frequency, the MC oscillation begins to lag behind the oscillation field polarity. Consequently, EHDI effect decreases and eventually disappears. Next, the scattering is characterized by stepwise changing the $\mathrm{AC}$ voltage from 0 to $30 \mathrm{~V}_{\mathrm{rms}}$ at $50 \mathrm{~Hz}$ (Figure 3c). The scattering was measured at a wavelength of $700 \mathrm{~nm}$ to avoid the absorption band of MC. Under ambient conditions without UV illumination, the sample exhibits a constant high optical transmission with increasing voltage. Only when voltage 

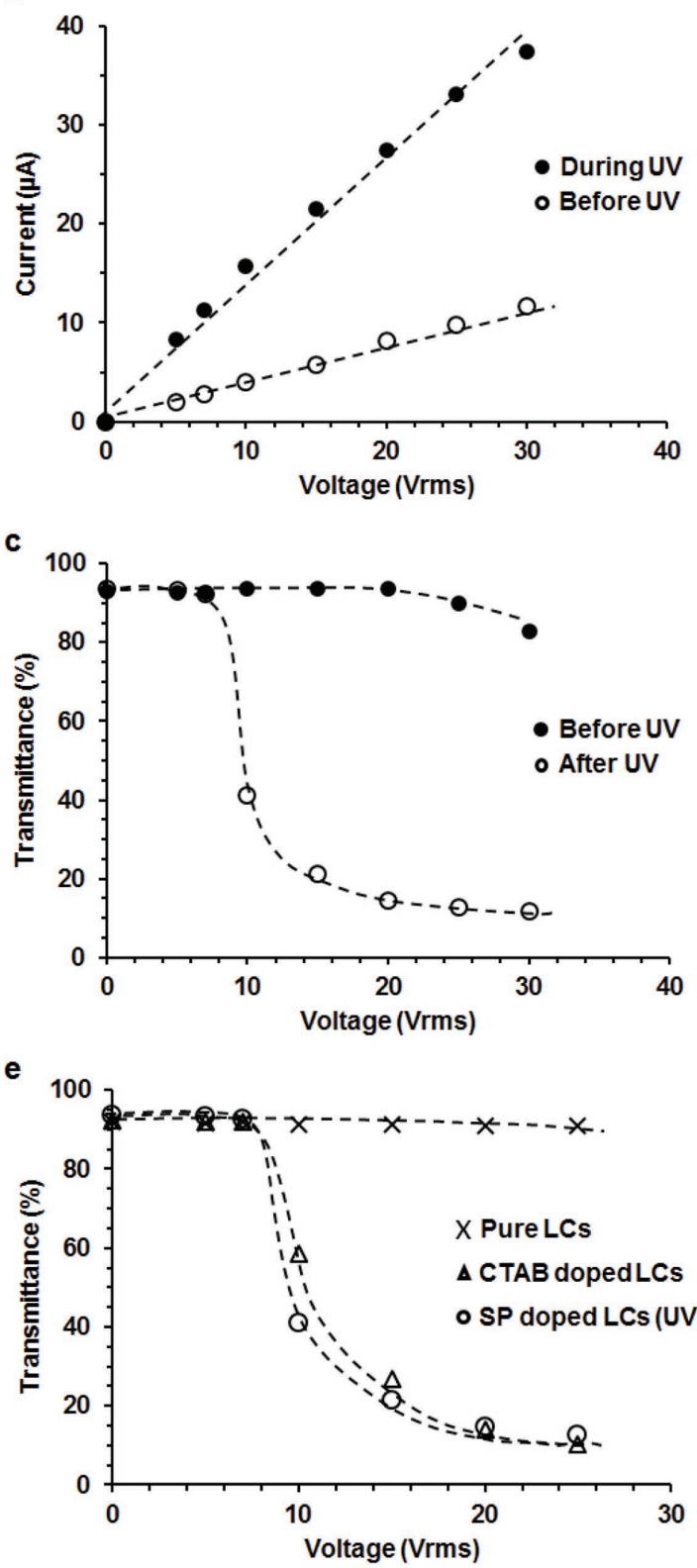

b

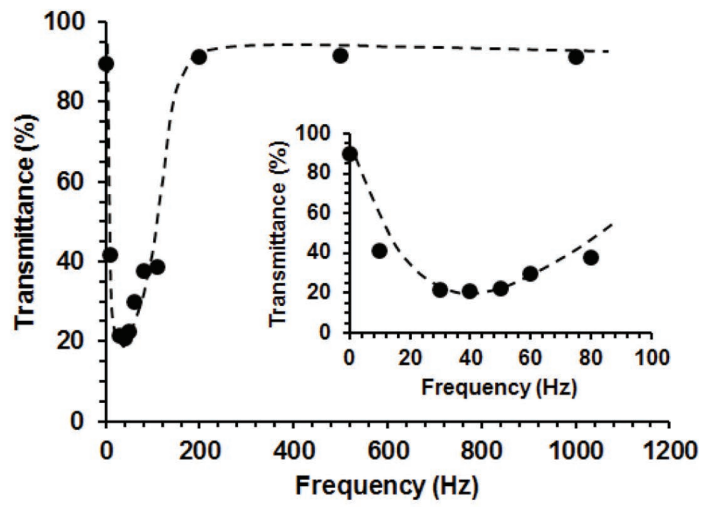

d

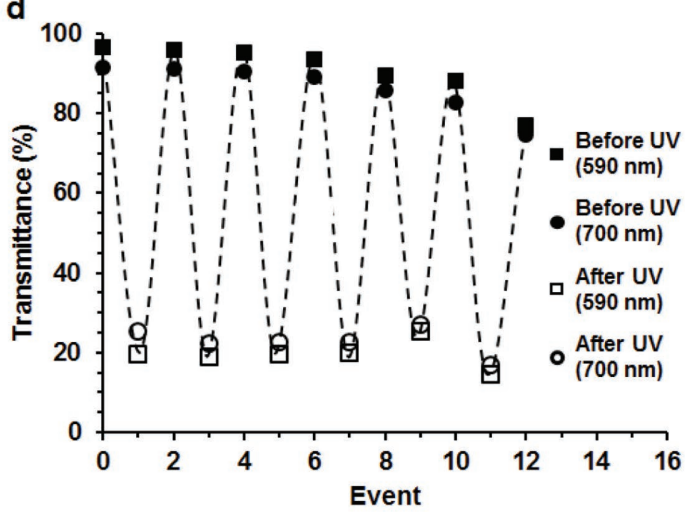

f

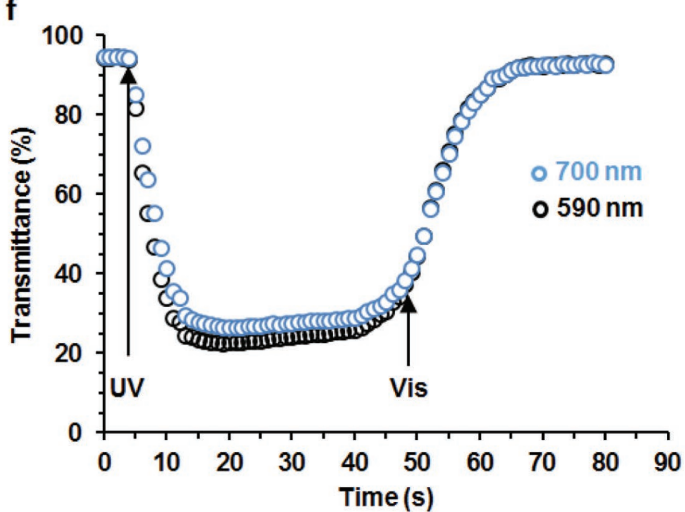

Figure 3. Characterization of light-induced EHDI. a) Current generated in the sample before and after EHDI is initiated. b) Influence of frequency on the light scattering. c) Voltage-dependent transmittance measured before and after UV light irradiation. d) Six switching cycles under the alternating UV and green light irradiation. The applied AC voltage is $20 \mathrm{~V}_{\mathrm{rms}}$ at $50 \mathrm{~Hz}$. The time interval between every two cycles is $2 \mathrm{~min}$. e) Comparison of the transmittance at $700 \mathrm{~nm}$ between samples with pure LC, electrolyte CTAB and SP-doped LC. f) Response kinetics of spiropyran conversion and corresponding scattering under UV and green light exposure. The exposure conditions for all experiments are $18 \mathrm{~mW} \mathrm{~cm}^{-2}$ at $365 \mathrm{~nm}$ and $7 \mathrm{~mW} \mathrm{~cm}^{-2}$ at $530 \mathrm{~nm}$. The cell gap is $9 \mu \mathrm{m}$.

exceeds $30 \mathrm{~V}_{\mathrm{rms}}$, the transmittance of the sample deceases slightly. Upon UV illumination, the transmittance drops dramatically to $16 \%$ at $20 \mathrm{~V}_{\mathrm{rms}}$ as the result of the EHDI effect. Note that in the experiments, the ultraviolet-visible spectra are taken directly after UV illumination.

By alternating the UV and green light exposure, the cell can be switched between the scattering and transparent state (Figure 3d). When measuring the transmittance at $590 \mathrm{~nm}$ which is the absorption maximum of $\mathrm{MC}$ it can be seen that the transmittance in the scattering state is low while it is high in the transparent state (Figure S6, Supporting Information). This clearly shows that the scattering is caused by the formation of $\mathrm{MC}$ while in the transparent state the SP form is present. We further notice that the sample does not completely recover to its initial transmittance after several switching cycles which might be ascribed to a small fraction of MC still present after green light exposure. ${ }^{[20]}$ It should be noted that the sample can fully relax back to the initial state at an elevated temperature. When comparing the EHDI effect between samples with pure LC, electrolyte CTAB-doped LC and SP-containing LC upon 
applying an AC field, the pure LC sample as expected does not exhibit EHDI effect (Figure 3e). The light exposed SP-LC and CTAB-LC devices show comparable transmittance change suggesting similar EHDI behavior. The transmittance can also be adjusted by the AC field strength, as seen in Figure 3c,e. Above the threshold voltage, the LC breaks into small domains and moderate light scattering is induced. Further increasing the voltage generates the chaotic turbulence in LCs and results in the maximum light scattering.

In order to quantify the response kinetics, we measured the time-resolved transmittance of SP in the LC and the lightinduced scattering by taking ultraviolet-visible spectra at 590 and $700 \mathrm{~nm}$, respectively. Results are given in Figure 3f. It is obvious that the LC light scattering occurs simultaneously with the SP to MC conversion without any phase lag. The back relaxation from $\mathrm{MC}$ to $\mathrm{SP}$ and the ceasing of light scattering are also synchronized and take $10 \mathrm{~min}$ in the dark (Figure S4, Supporting Information). The back reaction can be accelerated to $20 \mathrm{~s}$ by exposing the sample to green light. For reference, we performed an identical experiment with SP dissolved in tetrahydrofuran as solvent (Figure S7, Supporting Information). Results indicate that LCs matrix does not influence the isomerization of the photochemical reaction of spiropyran.

In order to demonstrate a light-rewritable patterned scattering device, we performed a mask-wise UV exposure as illustrated in Figure 4a-d (Movies S1-S3, Supporting Information). The projected flower pattern gives a conversion from transparent to blue and opaque, which is caused by the absorption of MC isomer and the EHDI-induced light scattering, respectively. The scattering pattern can be erased when addressed with a high frequency voltage, for example, $1 \mathrm{kHz}$ (Figure 3b) or by switching off the electric field. Both methods remove the EHDIinduced light scattering while keeping the light-induced $\mathrm{MC}$ pattern (Figure 4e). The entire pattern can be erased by green light converting the colored MC isomer to the SP colorless form. The printed pattern can also be erased locally through focused green light (Figure 4f). Currently, most e-writer tablets provide a global erasing possibility. Based on our technology, we
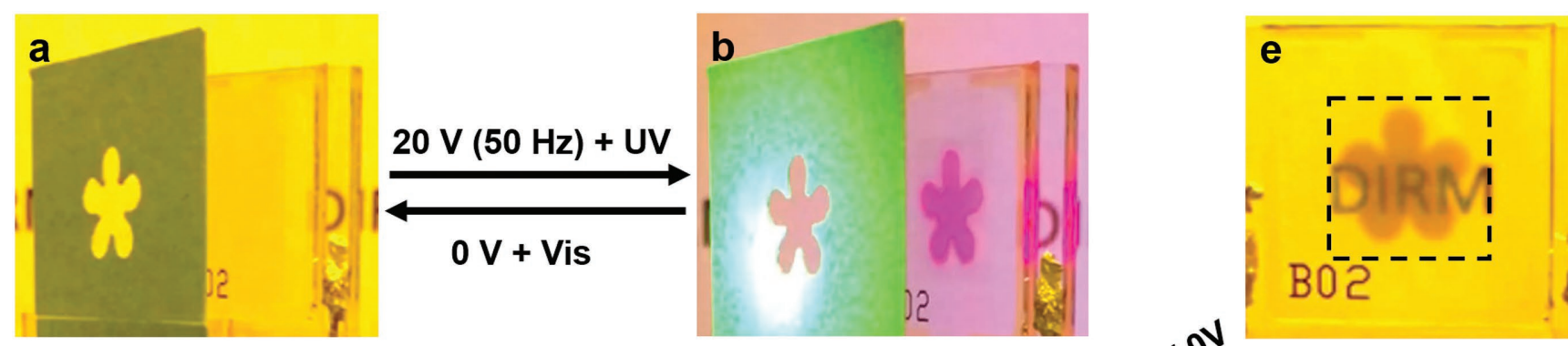
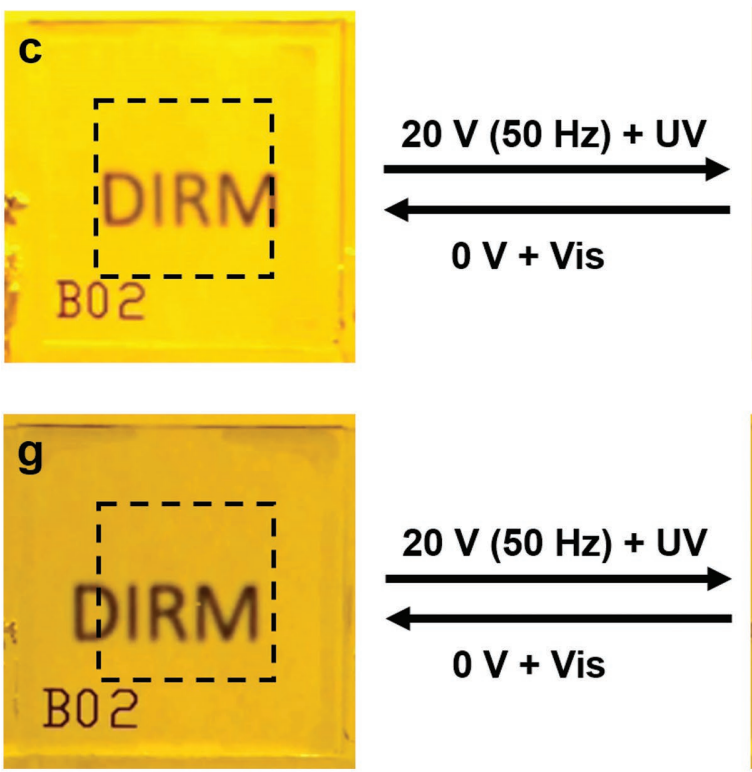
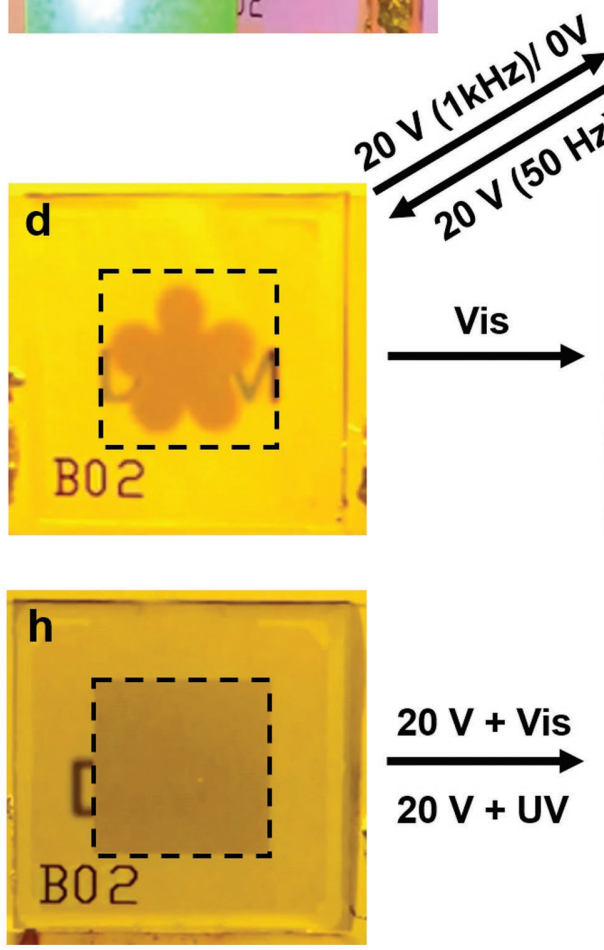
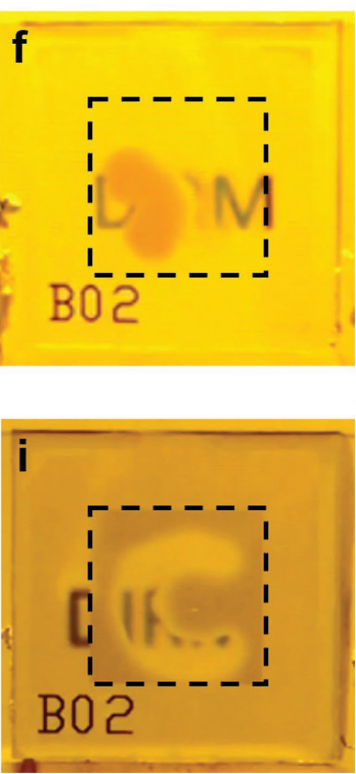

Figure 4. Photos show that EHDI can be locally generated and erased. a,b) The blue opaque flower is generated. c,d) The corresponding front view of (a) and (b), respectively. e) The blossom is partially erased by focused green light. f) The blue opaque flower turns into transparent when addressed with high-frequency voltage or switching off the AC field. g-i) Direct writing on the EHDI background through focused green light. All the samples are kept in the laboratory with yellow light to prevent MC to SP back reaction. The electric active area is highlighted by the dotted square. The voltage described in the pictures is root-mean-square voltage. The cell provides homeotropic alignment and the cell gap is $9 \mu \mathrm{m}$. 
propose a complementary solution to partially erase the display while keep the desired information on the display as shown in Figure 4f. Besides displaying preprogrammed information, for example, by patterned electrodes or by masked exposure, direct writing is enabled by using a focused light source (Figure 4g-i). In this experiment, the colored EHDI scattering provides the background while the focused green light partially erases EHDI and leaves information on scattering sample.

In conclusion, we have presented a new approach in initiating electrohydrodynamic instabilities in liquid crystals under light illumination. EHDI can be triggered or removed by alternating UV and green light exposure within tens of seconds. We especially explore the light scattering effect originated from EHDI in which the sample can be modulated from nearly $100 \%$ transparent state to $16 \%$ transmittance. The light scattering from EHDI exhibits a strong shielding effect which is proposed to be useful in smart window applications. Using light to trigger EHDI provides possibilities to localize light scattering by mask-wise exposure or by local writing with a focused beam. We anticipate the use of the effect for an information display or a smart window in which the messages can be written, stored, and erased, either locally or globally. In addition, this technology possesses large potential applications, such as the dye-doped colored windows, segmented triggered window, and e-paper.

\section{Experimental Section}

Materials: $7^{\prime}, 3^{\prime}$-Dihydro-1', $3^{\prime}, 3^{\prime}$-trimethyl-6-nitrospiro[2H-1-benzopyran$2,2^{\prime}-(2 \mathrm{H})$-indole] (spiropyran) was obtained from Sigma-Aldrich. CTAB was purchased from Sigma-Aldrich. LCs with negative dielectric anisotropy were obtained from Jiangsu Hecheng Advanced Materials Co., Ltd. (HNG30400-200, $T_{\mathrm{N}-1}=94{ }^{\circ} \mathrm{C}, \Delta \varepsilon=-8.3, \Delta n=0.149$ ). The conventional EHDI mixture contains 0.05 wt\% CTAB and 99.95 wt $\%$ LCs. The light-induced EHDI mixture contains $0.3 \mathrm{wt} \%$ of spiropyran and $99.7 \mathrm{wt} \%$ LCs.

Sample Preparation: Commercial cells (S100A090uT80, Instec; and XGH3030-10, Guohua Star) were used for experiments. The cells were filled with LC mixture at by capillary suction at $120{ }^{\circ} \mathrm{C}$. The samples were cooled slowly to $80^{\circ} \mathrm{C}$ and held for $2 \mathrm{~h}$ to eliminate any thermal instability before further cooled down to room temperature.

Sample Characterization: Samples were checked by optical microscope equipped with crossed polarizers (Nikon Ci Eclipse). Transmittance of the sample was measured by UV-vis-NIR spectrometer (PerkinElmer 750 and Ocean Optics HR2000+). The alternating electric field with a sinusoidal wave function was provided by a function generator $(33220 \mathrm{~A}$, Agilent). The electric signal from the function generator was amplified through a high-voltage linear amplifier (F20A, FLC Electronics). The output voltage was measured by an oscilloscope (DSOX3032T, Keysight). A LED lamp (M365L2 and M530L3-C2, Thorlabs) was used to provide monochromatic light.

\section{Supporting Information}

Supporting Information is available from the Wiley Online Library or from the author.

\section{Acknowledgements}

The results presented are part of research programs financed by the National Natural Science Foundation of China (51561135014,
U1501244), Guangdong Innovative Research Team Program (No. 2013 (102), European Research Commission under ERC Advanced Grant 66999 (VIBRATE), the framework of the 4TU.High-Tech Materials research program "New Horizons in designer materials" (www.4tu. $\mathrm{nl} / \mathrm{htm}$ ), and NWO VENI grant 15135, and additional information is available in the Supporting Information and from the authors.

\section{Conflict of Interest}

The authors declare no conflict of interest.

\section{Keywords}

electrohydrodynamic instabilities, light scattering, liquid crystals, photochemistry

Received: December 22, 2017

Revised: February 26, 2018 Published online:

[1] P. G. deGennes, J. Prost, The Physics of Liquid Crystals, 2nd ed., Clarendon, Oxford, UK 1993.

[2] a) W. D. S. John, W. J. Fritz, Z. J. Lu, D. K. Yang, Phys. Rev. E 1995, 51, 1191; b) D. J. Broer, J. Lub, G. N. Mol, Nature 1995, 378, 467; c) J. Xiang, Y. N. Li, Q. Li, D. A. Paterson, J. M. D. Storey, C. T. Imrie, O. D. Lavrentovich, Adv. Mater. 2015, 27, 3014; d) W. Hu, H. Y. Zhao, L. Song, Z. Yang, H. Cao, Z. H. Cheng, Q. Liu, H. Yang, Adv. Mater. 2010, 22, 468.

[3] a) S. N. Lee, L. C. Chien, S. Sprunt, Appl. Phys. Lett. 1998, 72, 885; b) D. Q. Liu, D. J. Broer, Langmuir 2014, 30, 13499; c) P. J. Ackerman, J. van de Lagemaat, I. I. Smalyukh, Nat. Commun. 2015, 6, 6012; d) C. P. Chiu, T. J. Chiang, J. K. Chen, F. C. Chang, F. H. Ko, C. W. Chu, S. W. Kuo, S. K. Fan, J. Adhes. Sci. Technol. 2012, 26, 1773.

[4] a) J. Fergason, SID Int. Symp. Dig. Tech. Pap. 1985, 16, 68; b) R. A. M. Hikmet, Adv. Mater. 1992, 4, 679; c) R. A. M. Hikmet, H. Kemperman, Nature 1998, 392, 476; d) F. Liu, J. J. Wang, Z. H. Ge, K. X. Li, H. J. Ding, B. P. Zhang, D. Wang, H. Yang, J. Mater. Chem. C 2013, 1, 216; e) F. Vicentini, J. L. Cho, L. C. Chien, Liq. Cryst. 1998, 24, 483; f) K. G. Gutierrez-Cuevas, L. Wang, Z. G. Zheng, H. K. Bisoyi, G. Q. Li, L. S. Tan, R. A. Vaia, Q. Li, Angew. Chem., Int. Ed. 2016, 55, 13090.

[5] D. K. Yang, L.-C. Chien, Liquid Crystals in Complex Geometries, Taylor and Francis, London, UK 1996.

[6] a) R. A. M. Hikmet, J. Appl. Phys. 1990, 68, 4406; b) R. A. M. Hikmet, Liq. Cryst. 1991, 9, 405; c) J. W. Doane, N. A. Vaz, B.-G. Wu, S. Zumer, Appl. Phys. Lett. 1986, 48, 269.

[7] a) R. A. M. Hikmet, Liq. Cryst. 2006, 33, 1410; b) I. Dierking, Adv. Mater. 2000, 12, 167; c) H. Khandelwal, A. P. H. J. Schenning, M. G. Debije, Adv. Energy Mater. 2017, 71602209.

[8] Y. K. Fung, D.-K. Yang, Y. Sun, L. C. Chien, S. Zumer, J. W. Doane, Liq. Cryst. 1995, 19, 797.

[9] a) R. Williams, J. Chem. Phys. 1963, 39, 384; b) R. Williams, Nature 1963, 199, 273; c) G. H. Heilmeier, L. A. Zanoni, L. A. Barton, Appl. Phys. Lett. 1968, 13, 46; d) G. H. Heilmeier, L. A. Zanoni, L. A. Barton, Proc. IEEE 1968, 56, 1162; e) L. M. Blinov, V. G. Chigrinov, Electrooptic Effects in Liquid Crystal Materials, Springer, New York 1996.

[10] a) J. Sun, R. C. Lan, Y. Z. Gao, M. Wang, W. S. Zhang, L. Wang, L. Y. Zhang, Z. Yang, H. Yang, Adv. Sci. 2018, 5, 1700613; b) J. Geng, C. Dong, L. P. Zhang, Z. Ma, L. Shi, H. Cao, H. Yang, 
Appl. Phys. Lett. 2006, 89, 081130; c) A. Jákli, L.-C. Chien, D. Krüerke, H. Sawade, G. Heppke, Liq. Cryst. 2002, 29, 377.

[11] a) P. Song, Y. Z. Gao, F. F. Wang, L. Y. Zhang, H. Xie, Z. Yang, H. Yang, Liq. Cryst. 2015, 42, 390; b) P. Song, H. Cao, F. F. Wang, F. Liu, H. Yang, Liq. Cryst. 2012, 39, 433; c) Y. Z. Gao, W. H. Yao, J. Sun, H. M. Zhang, Z. D. Wang, L. Wang, D. K. Yang, L. Y. Zhang, H. Yang, J. Mater. Chem. A 2015, 3, 10738.

[12] a) M. I. Barnik, L. M. Blinov, M. F. Grebenkin, S. A. Pikin, V. G. Chigrinov, Phys. Lett. A 1975, 51, 175; b) E. Kochowska, S. Németh, G. Pelzl, Á. Buka, Phys. Rev. E 2004, 70, 011711; c) B. R. Zhang, H. Kitzerow, J. Phys. Chem. B 2016, 120, 6865; d) S. V. Serak, U. Hrozhyk, J. Hwang, N. V. Tabiryan, D. Steeves, B. R. Kimball, Appl. Opt. 2016, 55, 8506.

[13] a) S. Kai, K. Hayashi, Y. Hidaka, J. Phys. Chem. 1996, 100, 19007; b) H. Richter, A. Buka, I. Rehberg, Phys. Rev. E 1995, 51, 5886; c) Y. Hidaka, J.-H. Huh, K. Hayashi, S. Kai, M. Tribelsky, Phys. Rev. E 1997, 56, 6256

[14] E. F. Carr, Mol. Cryst. 1969, 7, 253.

[15] a) A. Martinez, I. I. Smalyukh, Opt. Express 2015, 23, 4591; b) M. E. McConney, A. Martinez, V. P. Tondiglia, K. M. Lee,
D. Langley, I. I. Smalyukh, T. J. White, Adv. Mater. 2013, 25, 5880; c) H. Zeng, O. M. Wani, P. Wasylczyk, R. Kaczmarek, A. Priimagi, Adv. Mater. 2017, 29, 1701814; d) A. H. Gelebart, D. I. Mulder, M. Varga, A. Konya, G. Vantomme, E. W. Meijer, R. L. B. Selinger, D. J. Broer, Nature 2017, 546, 632.

[16] H. K. Bisoyi, Q. Li, Chem. Rev. 2016, 116, 15089.

[17] a) R. Klajn, Chem. Soc. Rev. 2014, 43, 148; b) J. ter Schiphorst, M. van den Broek, T. de Koning, J. N. Murphy, A. P. H. J. Schenning, A. C. C. Esteves, J. Mater. Chem. A 2016, 4, 8676; c) W. Li, X. R. Wu, H. Qin, Z. Q. Zhao, H. W. Liu, Adv. Funct. Mater. 2016, 26, 3164; d) J. E. Stumpel, B. Ziolkowski, L. Florea, D. Diamond, D. J. Broer, A. P. H. J. Schenning, ACS Appl. Mater. Interfaces 2014, 6, 7268; e) M. H. Zhang, X. Hou, J. T. Wang, Y. Tian, X. Fan, J. Zhai, L. Jiang, Adv. Mater. 2012, 24, 2424.

[18] C. D. Sheraw, L. Zhou, J. R. Huang, D. J. Gundlach, T. N. Jackson, M. G. Kane, I. G. Hill, M. S. Hammond, J. Campi, B. K. Greening, J. Francl, J. West, Appl. Phys. Lett. 2002, 80, 1088

[19] M. Urbanski, J. P. F. Lagerwall, J. Mater. Chem. C 2016, $4,3485$.

[20] T. Seki, K. Ichimura, J. Phys. Chem. 1990, 94, 3769. 